\title{
Quality health care delivery at health facilities in the ministry of health and social services in Namibia
}

\begin{abstract}
A quantitative and descriptive study was used to determine quality health care delivery at health facilities in the Ministry of Health and Social Services in Namibia (MoHSS). The purpose of the study was to identify the challenges within the health facilities as basis for development of quality improvement training programme for health professionals. A checklist was administered to determine the present situation of quality health care/service delivery at health care facilities. The target population were the managers in leadership positions, such as deputy permanent secretary, undersecretary, directors, pharmacist, medical superintends, principle medical officers, medical officers, health programme officers, matrons, senior officers and others

A total of twenty-one $(\mathrm{n}=21)$ participants were purposively selected, which comprised managers in leadership $(n=6)$ from the MoHSS head office and regional health directorates (regional management teams). $(n=15)$ from the health facilities, Apart from the demographic data, participants were given opportunity to rate quality health care delivery on Likert's scale with scores ranged from strongly disagree; disagree, agree and do not know on the following variables, such as policies and guidelines; leadership; human, physical, material and financial resources; patient safety, information as well as monitoring and evaluation.

The Statistic Package for Social Sciences (SPSS) software was used for data analysis Data were presented in percentages, figures and tabular formats. To ensure reliability, items in the checklist were tested using the Cronbach alpha coefficient for multiple items measured on the Likert's scale. It was indicated that the items from one to forty (1-40) provided a value of 0.95 while the rest of items (measures) was 0.88 . For validity, content, criterion and construct were used. The findings of this objective revealed some ambiguities in the availability of policies and guidelines, leadership to facilitate care delivery, health system infrastructure, patient safety, as well as research and information to facilitate quality health delivery.
\end{abstract}

Keywords: quality health care, delivery and health facilities, statistic package for social sciences, quality assurance, MoHSS

\author{
Volume 2 Issue I - 2017
}

\author{
Amukugo Hans Justus,' Julia Paul Nangombe ${ }^{2}$ \\ 'Department of Public health, University of Namibia, Namibia \\ 2Department of Quality Assurances and Quality Improvement, \\ Namibia
}

Correspondence: Amukugo Hans Justus, Department of Public health, University of Namibia, Namibia, Email hamukugo@unam.na

Received: November 15, 2016 | Published: January 19, 2017

\section{Introduction and background}

Health care facilities, as entities that are required to provide quality health care, can no longer remain static given the increasing demand and public pressure to improve quality health care. ${ }^{1}$ The National Quality Management System Report has pointed at the burden of staff shortages as one of the reasons for transferring some functions to inexperienced health personnel, at least one person (15.4\%) out of the staff complement at a health care facility, since the remaining staff members had to attend to long queues with no time to focus on quality. ${ }^{2}$ Most health care systems have existing quality assurance (QA) standards but often these standards are not properly followed to respond to the needs of the clients. ${ }^{3}$ On the other hand, absence of rewards and a recognition system seem to contribute to poor quality health care delivery by the MoHSS. At the time of this study, there were no effective strategies to retain or attract health professionals to the public health sector. More than sixty per cent $(62.5 \%)$ of staff members at the assessed health care facilities indicated that staff recognition was only informally done by immediate supervisors but no incentive strategies existed to recognize good performance with the purpose of improving the quality of health care. The result of "... poor performance is few staff or staff not providing care according to standards and not being responsive to the needs of the community and patients".
In Namibia, QA and QI activities depend to a large extent on effective management of resources (human, physical infrastructure, and finance). In addition, the components of quality health care and services are largely dependent on accessible health care and services to those people who need it. Offei Doyle et al. ${ }^{4}$ explain that a number of quality health care components influence the access and provision of health care and services. For example, access to quality health care can be used as an indicator for the ability of individuals to obtain health care and services.

Technical competencies are another aspect required to empower health professionals with adequate knowledge, skills, and aptitudes to provide excellent and professional care and services. Secondly, it facilitates the functions proficiently according to the standards of quality health care services. ${ }^{5}$ Hence, health professionals need to be empowered in order to provide the type of care that produces positive change in the patients' health or quality of life. The Ghanaian Ministry of Health has prioritized similar initiatives to improve quality of health services since 1989 and the country has been making advances to increase service coverage but their efforts have not yielded the anticipated improvements in health status; the quality of health services has actually declined. ${ }^{6}$ Furthermore, reports of irregularities and dissatisfied patients about the Ghanaian health system continue to surface in both electronic and print media 
in Namibia due to "...uneven health care quality, bad interpersonal relations and poor communication between health care providers and clients, mistreatment and missed-treatment". ${ }^{7}$ Similar sentiments were reckoned by Meyer et al. ${ }^{8}$ That the "...United States health care system consists of preventable errors, unnecessary surgeries and inappropriate use of medications, procedures, misuse and under services". In Namibia, the "...public health facilities are described by the public and health professionals to be below standards, overcrowding at outpatient department (OPD), long queues and long waiting times, as indicators of poor quality patient care". ${ }^{1}$ These and other problems raise serious concerns, which necessitate immediate actions to adopt appropriate methods to improve health care services.

In the context of quality management policy and positive improvement in the area of the HIV/AIDS programme in the MoHSS, there have not been comprehensive approaches to assist and empower health professionals with the necessary competencies to provide quality care at the health care facilities. At the time of this study, the focus of the health facilities was neither on systematic checks, safety controls, nor on significant activities on quality assurance training programmes. Other quality control mechanisms were scattered under different directorates.

On a policy framework, the Namibian Public Service outlines the principles that guide the actions of the public servants. Despite efforts, there seems to be no significant or deliberate underlying structure to constantly insist on holistic quality care measures. Consequences would include poor performance, ineffective communication, inappropriate systems, as well as demotivated and dissatisfied staff members and patients. Extreme risks may include escalating diseases, social problems, and a fragile health care system. Although the MoHSS has endeavored to reorganize and restructure some functions, no tangible results seem to focus on quality improvement at the public health care facilities. The main focus seems to be increasing the numbers of personnel to respond to emerging and re-emerging diseases and additional services. Countrywide, this approach has little or insignificant consideration for addressing quality care at the health care facilities. Often, public health care facilities are perceived as not performing and irresponsive to patient needs. Inappropriate methods, weaknesses, and negligence may result in a loss of lives due to ineffective practices and measures. Efficiencies in quality of care represent neither the failure of professional compassion nor necessarily a lack of resources rather a result from gaps in knowledge, inappropriate applications of available technology", ${ }^{9}$ or the inability of organizations to change. ${ }^{10}$ The absence of strong leadership and partnership may also jeopardize an effective and timely response to patients' needs. At the time of the study, there seemed to be no appreciation or persuasion of quality approaches to help leaders and employees address quality care problems at the health care facilities. Research presents several models applicable to the health care environment but few or nonspecific studies are focusing on quality improvement at public health care facilities in Namibia. Without a common understanding of quality improvement principles and the value of health care realities, patients' care might be compromised.

\section{A need exists, therefore, to}

a. Broaden the knowledge about quality improvement.

b. Assist managers, employees, and patients to appreciate quality improvement models.

c. Apply practical tools or techniques to improve quality care. d. Encourage active participation and involvement of all stakeholders in quality health care delivery.

The main focus of this study was to develop a quality improvement training programme, which focused on a situation analysis to understand the approaches on QI and QI to improve health care and service delivery.

\section{Aim and objectives}

The aim of study was to analyze the status of quality health care delivery at health facilities Ministry of Health and Social Services in Namibia.

\section{Methodology}

The study focused on the analysis of the status of quality health care delivery at health care facilities. To achieve this, the population, sample and sampling method, data collection, data analysis and validity and reliability are described as follow: The population comprised of managers in leadership positions, which included the Permanent Secretary, Undersecretaries, Deputy Permanent Secretary, Directors, Senior Medical Superintended, Deputy Directors and regional health directors

Sampling is the process of selecting cases to represent a population in order to make inferences about the population while a sample refers to a subset of the units about which data will be collected..$^{11}$ In this objective, a total of twenty-one $(n=21)$ participants were purposively selected, who comprised of managers in leadership $(n=6)$ from the MoHSS head office as well understudy regional health directorates $(\mathrm{n}=15)$ in Khomas (Windhoek), Kunene (Opuwo), Erongo (Swakopmund) and Omusati (Outapi), as illustrated in Table 1. The regions were selected based on geographical location, population density.

Table I Categories of participants per region

\begin{tabular}{llll}
\hline Region & Managers/leadership & $\begin{array}{l}\text { Health } \\
\text { professionals }\end{array}$ & $\begin{array}{l}\text { Number of } \\
\text { participants }\end{array}$ \\
\hline Khomas & 6 & 4 & 10 \\
Kunene & I & 3 & 4 \\
Erongo & I & 3 & 4 \\
Omusati & I & 2 & 3 \\
Total & 9 & 12 & 21 \\
\hline
\end{tabular}

\section{The following inclusion criteria were utilised}

A manager in leadership position at MoHSS head office, regional health directorates or hospitals. Expatriates-managers in leadership position for more than three years. Interested or willing to participate and provides a written informed consent, as a respondent in the study. A trained in health professional related fields registered or recognised by the Health Professional Council of Namibia and Namibia Qualification Authority, and working at the selected health care facilities in the specified regions.

A checklist (Annexure J) was developed in order to meet phase one of the study. The layout of the checklist was demarcated into two sections; namely section A focused on demographic data such as age, gender, level of education, years in current position, primary 
role at the health care facility, and current job description. Section B was on the variables for quality assurance and quality improvement such policies and guidelines; leadership; human, physical, material and financial resources; patient safety, research and information, as well as monitoring and evaluation was developed. These variables were derived from the Deming's PDSA model and MoHSS National Quality Management Policy. ${ }^{12}$

The respondent managers in leadership position were required to indicate their level of agreement on different statements of closedended questions on a checklist of 1-6 level scale. In this study, a Likert scale was adopted to measures ordinal variables with response options "Strongly disagree"; "disagree"; "neutral"; "agree", "strongly agree" and "don't know" to indicate the level of agreement. Further checklist included statements on research ethics and utilization of data whereby the participants would be given a statements of "yes", "no" and don't know to choose.

The researcher prepared the checklist with assistance of the qualified statistician as well as guidance by the supervisor in a self administered format. This was done in accordance of Andre, ${ }^{13}$ which states that a self-administered checklist requires that the respondents would be able to complete without assistance by the researcher. Since the respondents were experienced in the field understudy and articulated the language used in the documents, they had no difficulties in completing the checklist. Part of this was also attributed to the facts that the checklist was piloted and the results were incorporated.

The checklist was distributed by the researcher assisted by the trained assistant researchers. The checklist was distributed concurrent with interviews and focus group discussion (objective 2) during the stipulated day allocated to specific region, prior arranged schedules. The respondents were expected to complete the questionnaires within 30 to 60 minutes and expected to return them immediately to the assistant researchers.

The reliability of a measure denotes the level of consistency of the items (dimensions) or measurement and the unbiased approach during a period of time across multiple items. ${ }^{14}$ Reliability is a measure of stability and consistency with which an instrument measures a particular concept. ${ }^{15}$ In this study, the reliability of items was tested using the Cronbach alpha coefficient for the multiple items measured on six points scale. The higher the coefficient the better or reliable the measuring instrument. ${ }^{15}$

Nunnally ${ }^{16}$ suggests that in studies with substantial samples from a larger population, the reliability is expected to display a Cronbach alpha coefficient above 0.9 ; however, values ranging from 0.7 are acceptable indicators of internal consistency. In this research study, the Cronbach alpha coefficient indicated that items (measures) from 1-40 provided a value of 0.95 while the value for the rest of the items (measures) was 0.88 . This signified that both items were significantly very high, which indicated that the tool used was reliable and consistent. It can be stated that the tool did, therefore, measure what it had intended to measure and produced reliable data that could be applied in any health care facility context in similar situations.

A measure is considered valid when it actually measures what it is intended to measure..$^{17}$ The instrument used in this research study was a combination of instruments used in previous studies, hence it had both content and criterion validity. Validity ensures the ability of a scale to measure the intended concept, as explained by Sekaran ${ }^{14}$ that research uses three types of validity: Content validity, criterion validity, and construct validity. In this study, for the content validity the research instrument was generated through intensive literature review of national and international policies and guidelines on QI and QA; use of experts in the field; the checklist was designed in line with the objectives. ${ }^{18,19}$ To ensure criterion validity, prior the commencement of the study the instrument was piloted to ensure the extent to which it correspond to or correlate with some of the criterion measures or the variables in QI and QA. For construct validity, the instrument was designed to Table 2 measure specific aspects regarding QI and QA. This was done in the form of Likert scale, as illustrated in Chapter 2 and Annexure J. ${ }^{20}$

Table 2 Reliability statistics-cronbach's alpha coefficient

\begin{tabular}{ll}
\hline Cronbach's alpha co-efficient & $\mathbf{N}$ of items \\
\hline 95 & Jan-40 \\
88 & $40-42$
\end{tabular}

No of cases $=12$.

A descriptive statistical analysis was used to organise, clarify and simplify the data into meaningful concepts. In this research, the data was presented in frequencies, tabular form consisting of percentages and categories, such as sex, gender to describe the variables. ${ }^{21}$

For data entry, editing and handling, immediately after the checklists were collected, the researcher and assistant researchers checked if the checklist was correctly completed ${ }^{22}$ and ready for coding and transfer into excel spread sheet. These involved checking and adjusting the collected information to ensure consistency, omissions and legibility. For the errors and missing information identified, the researchers went back to the specific respondents since the checklist were coded. ${ }^{23}$

The researchers developed ${ }^{24}$ a process of coding and recording by means of database for all respondents. The checklists were entered in data base for computerised data analysis. Data were cleaned for accurateness and appropriateness. The data was then stored and handed to the statistician for further analysis. ${ }^{25}$

The data were stored in the researcher's computer as well in the "Drop box" for purpose of retrieval and accessibility. The researcher provides each respondent with a number or code name, which were during discussions or interpreting data and the ${ }^{26}$ researcher was the only one accessible to the stored data. The completed checklists were stored in a lockable cabinet to ensure the anonymity. For confidentiality, the researcher ensured that no information was divulged or made available to any person except the statistician. ${ }^{27}$

The Statistical Package for Social Sciences software was used for data analysis. The data were presented in percentages, figures and tables. ${ }^{28}$ To ensure reliability and consistency of data, items in the checklist were tested using the Cronbach's alpha coefficient for multiple items measured on the Likert's scale. ${ }^{29} \mathrm{~A}$ Cronbach's alpha is statistical measure of internal consistency, that focuses on how closely related a set of items are as a group.

The study followed certain procedures as part of the research principles and standards guiding research protocols. The researcher was very careful to abide by the procedures to ensure that neither the rights of participants were violated, nor were the properties of the research permission by the MoHSS management infringed upon. ${ }^{30}$ Research ethics are defined as agreed social norms, principles, and standards that regulate research protocols to minimise undesirable 
actions or behaviour in conducting research, especially research that involves human subjects. In this study, five main ethical principles were observed. ${ }^{31}$

Permission to conduct the study at the health care facilities was granted by the University of Namibia (Annexure A); MoHSS (Annexure B), Researcher Proposal to conduct research in the health facilities (Annexure C) and Registration of a research project by MoHSS (Annexure E). Although approval letters were couriered to all the Regional Health Directors, some health care facilities did not receive the letters. The researcher had to follow up with specific Health Regional Directors, Senior Medical Superintendents, Principal Medical Officers, and Nurse Managers and letters were either faxed, or scanned and emailed to them. Telephone calls were made to confirm the dates and times of the scheduled interviews and focus group discussions. In addition, before entering the research venue, each participant was requested to sign an informed consent form to indicate his/her willingness to participate in the study. ${ }^{32}$ In the consent from, participants were assured of the ethical principles and rules pursued in this study. Participants in this study were provided with sufficient information about the research right to enable them to participate or not. ${ }^{33}$

\section{Results and discussion}

The analysis of demographic data included age, gender, occupation, and years in current position or duration of work, education attained/ level of education, as well as primary roles. The data was collected from respondents through a self-administration checklist that consisted of statements measured on a Likert scale of agree, neutral, disagree, yes and no, as illustrated in the annexure $\mathrm{J}$.

\section{Socio-demographic characteristics of respondents}

The socio-demographic data was used to understand the characteristics of respondents in their capacity as managers in leadership positions and health professionals in the MoHSS, as interpreted in Table 3 below.

Table 3 Socio-demographic characteristics of respondents

\begin{tabular}{llll}
\hline Item & Count $(\mathbf{n}=\mathbf{2 1})$ & $\%$ & Cumulative \% \\
\hline Age (year) & 5 & & \\
$35-45$ & 13 & 24 & 24 \\
$45-55$ & 3 & 62 & 86 \\
$55>$ & 14 & 100 \\
Gender & 13 & & \\
Male & 8 & 62 & 62 \\
Female & 38 & 100 \\
Occupation & 1 & & \\
Deputy permanent secretary & 1 & 5 & 5 \\
Under secretary & 2 & 10 & 15 \\
Directors & 3 & 14 & 29 \\
Pharmacist & 1 & 5 & 34 \\
Medical superintendents & 2 & 10 & 44 \\
\hline
\end{tabular}

Table Continued....

\begin{tabular}{|c|c|c|c|}
\hline Item & Count $(n=2 I)$ & $\%$ & Cumulative \% \\
\hline Principal medical officers & 2 & 10 & 54 \\
\hline Health programme officers & 3 & 14 & 68 \\
\hline Matron & 4 & 19 & 87 \\
\hline Senior personnel officer & I & 5 & 92 \\
\hline Other & 2 & 10 & 100 \\
\hline \multicolumn{4}{|l|}{ Duration of work } \\
\hline 2 to 5 & 6 & 29 & 29 \\
\hline 5 to 10 & 8 & 38 & 67 \\
\hline 10 to 20 & 5 & 24 & 91 \\
\hline $20>$ & 2 & 9 & 100 \\
\hline \multicolumn{4}{|l|}{ Education attained } \\
\hline Primary & 0 & 0 & 0 \\
\hline Secondary & 0 & 0 & 0 \\
\hline Tertiary & 17 & 17 & 17 \\
\hline Other & 4 & 4 & 21 \\
\hline
\end{tabular}

\section{Age}

The majority of respondents $13(62 \%)$ were in the age range of $45-55$ years, $5(24 \%)$ were between $35-45$ years while $3(14 \%)$ were above 50 years.

\section{Gender}

The majority of the participants were male $13(62 \%)$ and $8(38 \%)$ were female. This explains the high dominance of males in top managerial positions. Despite the fact that health facilities were viewed as female dominated, the picture had changed, since more and more males were aspiring to high positions than their female counterparts. Further research might provide insight and interpretations into differences between gender and positions, as well as leadership qualities required by those at management levels to facilitate quality health care delivery. ${ }^{33}$ Regarding the level of education, as illustrate in Table $4,17(80 \%)$ had tertiary education while $4(20 \%)$ specified that they had competed Master of Public Health.

Table 4 Gender and age group cross tabulation

\begin{tabular}{llllll}
\hline \multirow{5}{*}{ Gender } & Count & $\mathbf{2}$ & $\mathbf{I}$ & $\mathbf{5}$ & $\mathbf{8}$ \\
\cline { 3 - 6 } & $\mathbf{5} 5 \mathbf{5}$ & $\mathbf{3 5 - 4 5}$ & $\mathbf{4 5 - 5 5}$ & Total \\
\cline { 3 - 6 } F & \% within Gender & $25,0 \%$ & $12,5 \%$ & $62,5 \%$ & $100,0 \%$ \\
M & Count & 1 & 4 & 8 & 13 \\
& \% within Gender & $7,7 \%$ & $30,8 \%$ & $61,5 \%$ & $100,0 \%$ \\
\multirow{2}{*}{ Total } & Count & 3 & 5 & 13 & 21 \\
& \% within Gender & $14,3 \%$ & $23,8 \%$ & $61,9 \%$ & $100,0 \%$ \\
\hline
\end{tabular}

\section{Duration in position}

In this research, the highest respondents in an occupational position 
ranged from 5-10 years which were 8(38\%), 2-5 years 6(29\%), 11-20 years were $5(24 \%)$, while $>21$ years were only $2(9 \%)$. The duration of work in a current position of the respondents, as a manager in leadership position ranged from 2 to 20 years, as indicated in sociodemographic characteristics section.

\section{Interpretation of statements on quality health care delivery}

The statements discussed in this research focused on the availability of policies and guidelines; leadership, human, physical, material, and financial resources; information, monitoring and evaluation; as well as research to facilitate quality health care delivery.

\section{Policies and guidelines to facilitate quality health care delivery}

In relation to policies and guidelines, respondents rated nine items Table 5.

Table 5 Frequencies on policies and guidelines $(n=21)$

\begin{tabular}{|c|c|c|c|}
\hline Statements /items & $\begin{array}{l}\text { Agree } \\
f(\%)\end{array}$ & $\begin{array}{l}\text { Neutral } \\
\text { f(\%) }\end{array}$ & $\begin{array}{l}\text { Disagree } \\
f(\%)\end{array}$ \\
\hline $\begin{array}{l}\text { Item I: There is a quality improvement policy and guidelines aligned to the } \\
\text { strategic objectives of the organisation to prioritise, identify, and address } \\
\text { gaps in quality health care delivery. }\end{array}$ & $17(8 \mid \%)$ & $3(14 \%)$ & $\mathrm{I}(5 \%)$ \\
\hline $\begin{array}{l}\text { Item 2: There are documented standards that guide health professionals } \\
\text { and ethic / steering committees to ensure appropriate conduct and } \\
\text { compliance to quality health care measures. }\end{array}$ & I5(7|.4\%) & $3(14.3 \%)$ & $3(14.3 \%)$ \\
\hline $\begin{array}{l}\text { Item 3: A written description of a formally agreed quality policy and plans } \\
\text { at both operational (health facility) and at national level are implemented. }\end{array}$ & $17(8 \mid \%)$ & $3(14 \%)$ & $\mathrm{I}(5 \%)$ \\
\hline $\begin{array}{l}\text { Item 4: There are health committees that encourage and support all } \\
\text { stakeholders' active participation in the quality improvement process. }\end{array}$ & $13(62 \%)$ & $3(14 \%)$ & $5(24 \%)$ \\
\hline $\begin{array}{l}\text { Item 5: There are clear guidelines on organisational levels of quality health } \\
\text { care delivery that are understood by all health care providers (operational } \\
\text { - facilities; intermediate - planners, policy - decision makers; strategic - } \\
\text { management). }\end{array}$ & $14(67 \%)$ & $2(10 \%)$ & $5(24 \%)$ \\
\hline $\begin{array}{l}\text { Item 6: There are incentive strategies (moral, material, or monetary) to } \\
\text { encourage participation in quality improvement programmes. }\end{array}$ & $17(81 \%)$ & $3(\mid 4.2 \%)$ & $\mathrm{I}(5 \%)$ \\
\hline $\begin{array}{l}\text { Item 7: The physical facility planning and maintenance are part of the } \\
\text { quality improvement policy to facilitate quality health care delivery. }\end{array}$ & $4(19 \%)$ & $3(14 \%)$ & $14(67 \%)$ \\
\hline $\begin{array}{l}\text { Item 8: There is well-defined Quality Improvement Checklists for } \\
\text { indicators and a Quality Inventory Plan for all essential supplies. }\end{array}$ & II (52\%) & $9(43 \%)$ & $\mathrm{I}(5 \%)$ \\
\hline $\begin{array}{l}\text { Item 9: Health facilities have operational feedback plans to respond to } \\
\text { patient concerns to facilitate good communication. }\end{array}$ & $12(7 \mid \%)$ & I(5\%) & $5(24 \%)$ \\
\hline
\end{tabular}

Item 1: Seventeen $(81 \%)$ of the participants agreed that the quality improvement policy and guidelines were aligned to organisations' strategic objectives to prioritise, identify, and address gaps in quality health care delivery at the health facilities; however, one $(5 \%)$ disagreed while three (14\%) were neutral.

Item 2: Fifteen (71\%) of the participants agreed that health facilities had standards, documents that guided health professionals, and ethic/ steering committees to ensure appropriate conducts and compliance to quality health care measures. However, three (14\%) remained neutral while one (5\%) disagreed.

Item 3: Seventeen $(81 \%)$ of the participants agreed that there were written descriptions of formally agreed quality policy and plans at both operational (health facility) and national levels but three (14\%) remained neutral while one (5\%) disagreed.

Item 4: Thirteen (62\%) agreed that health committees that encouraged and supported stakeholders' active participation in quality improvement processes existed at the health facilities, three (14\%) remained neutral while five (24\%) disagreed.
Item 5: Participants were given an opportunity to rate whether health facilities had clear guidelines on quality health care delivery at organisational level that were understood by all health care providers (operational - facilities, intermediate - planners, policy-decision makers, strategic-management). On this item, 14 (67\%) agreed, two $(10 \%)$ remained neutral while five $(24 \%)$ disagreed.

Item 6: In terms of the availability of incentive strategies (moral, materials, or monetary) to encourage participation in quality improvement programmes, $17(81 \%)$ participants agreed, three (14\%) were neutral while one (5\%) disagreed.

Item 7: Fourteen (19\%) participants agreed that physical facility planning and maintenance were part of the quality improvement policy to facilitate quality health care delivery, three (14\%) were neutral while 14(67\%) disagreed.

Item 8: Eleven (52\%) participants agreed that health facilities had welldefined Quality Improvement Checklists for indicators and Quality Inventory Plan for all essential supplies, nine (43\%) participants opted for neutral while one (5\%) participant did not support that statement. 
Item 9: Participants were given an opportunity to indicate whether health facilities had operational feedback plans to respond to patients' concerns to facilitate good communication. However, 12(71\%) agreed, one (5\%) was neutral while five (24\%) disagreed.

The majority of respondents (50\%-80\%) were in agreement with all the statements, which implied that policies and guidelines were available that could be enhanced to facilitate quality health care delivery. On other hand, the results from the FGDs with health professionals indicated that although policies and guidelines were available, often they were neither effectively implemented nor understood to address challenges experienced in quality health care delivery. It could be, therefore, concluded that although policies were available, often there was no common understanding to enhance effective implementation Table 6.

Table 6 Frequencies on leadership $(n=21)$

\begin{tabular}{llll}
\hline Statements & $\begin{array}{l}\text { Agree } \\
\mathbf{f ( \% )}\end{array}$ & $\begin{array}{l}\text { Neutral } \\
\mathbf{f ( \% )}\end{array}$ & $\begin{array}{l}\text { Disagree } \\
\mathbf{f ( \% )}\end{array}$ \\
\hline $\begin{array}{l}\text { Item I: There is visionary and strong leadership to ensure active } \\
\text { involvement of health professionals and stakeholders in setting priorities } \\
\text { for planning of quality health care improvement. }\end{array}$ & $\begin{array}{l}10(48 \%) \\
\begin{array}{l}\text { Item 2: Leadership provides guidance and coaching to staff members for } \\
\text { strategic planning and testing the process of quality improvement. }\end{array}\end{array}$ & $6(29 \%)$ & $5(24 \%)$ \\
$\begin{array}{l}\text { Item 3: Leadership supports employees to build commitment and } \\
\text { confidence in process analysis and quality improvement initiatives. }\end{array}$ & $12(57 \%)$ & $8(38 \%)$ & $1(5 \%)$ \\
$\begin{array}{l}\text { Item 4: Leadership encourages health professionals to design } \\
\text { interventions to improve quality care and service delivery. }\end{array}$ & $10(48 \%)$ & $3(14.2 \%)$ & $8(38 \%)$ \\
\hline
\end{tabular}

\section{Leadership to facilitate quality health care delivery}

On leadership to facilitate quality health care delivery at health

care facilities, participants were given four items to rate as illustrated in Table 7.

Table 7 Frequencies on human, physical, material, and financial resources $(n=21)$

\begin{tabular}{llll}
\hline Statements & $\begin{array}{l}\text { Agree } \\
\mathbf{f ( \% )}\end{array}$ & $\begin{array}{l}\text { Neutral } \\
\mathbf{f ( \% )}\end{array}$ & $\begin{array}{l}\text { Disagree } \\
\mathbf{f ( \% )}\end{array}$ \\
\hline $\begin{array}{l}\text { Item I: There are adequately trained health professionals to } \\
\text { facilitate quality health care delivery at all health facility levels. }\end{array}$ & $14(67 \%)$ & $3(14.2 \%)$ & $4(19 \%)$ \\
$\begin{array}{l}\text { Item 2: The resources (human, material, infrastructure, finance) } \\
\text { are equitably distributed and utilised to facilitate quality health care } \\
\text { delivery. }\end{array}$ & $8(38 \%)$ & $5(24 \%)$ & $8(38 \%)$ \\
$\begin{array}{l}\text { Item 3: There is internal budget to ensure successful } \\
\text { implementation of quality improvement programmes. }\end{array}$ & $9(43 \%)$ & $8(38 \%)$ & $4(19 \%)$ \\
$\begin{array}{l}\text { Item 4: The design and setting of health facility infrastructures do } \\
\text { meet agreed quality improvement standards to address patients' } \\
\text { health needs. }\end{array}$ & $13(62 \%)$ & $4(19 \%)$ & $4(19 \%)$ \\
$\begin{array}{l}\text { Item 5: There are quality teams consisting of health professionals, } \\
\text { management, patients, and stakeholders that analysis, evaluate, and } \\
\text { compare quality health care results. }\end{array}$ & $7(33 \%)$ & $8(38 \%)$ & $6(29 \%)$ \\
$\begin{array}{l}\text { Item 6: There is a continual professional development training } \\
\text { programme to improve quality health care delivery. }\end{array}$ & $10(48 \%)$ & $4(19 \%)$ & $7(33 \%)$
\end{tabular}

Item 1: There is visionary and strong leadership to ensure active involvement of health professionals and stakeholders in setting priorities for planning of quality health care improvement; ten (48\%) participants agreed, six (29\%) opted for neutral, and five (24\%) disagreed.

Item 2: Leadership provides guidance and coaching to staff members for strategic planning and testing the process of quality improvement; thirteen (62\%) agreed, one (5\%) remained neutral, and seven $(33 \%)$ disagreed.

Item 3: Leadership supports employees to build commitment and confidence in process analysis and quality improvement initiatives; twelve $(57 \%)$ agreed, eight remained neutral $(38 \%)$, one $(5 \%)$ disagreed.
Item 4: Leadership encourages health professionals to design interventions to improve quality care and service delivery; ten (48\%) agreed, three (14.2\%) remained neutral, and eight (38\%) disagreed.

The responses on leadership indicated a high percentage of $48 \%$ a $57 \%$ of respondents who were in agreement that the MoHSS had strong, committed, confident, and visionary leadership to empower employees to improve quality health care delivery. This statement was, however, opposed by the results from FGDs, which indicated that there was neither supportive leadership nor involvement in quality health care planning to assist health professionals in day-to-day scuffle to provide quality health care and meet the expectations of the clients (patients). Thus, it can be concluded that there were inadequate supportive supervision and low involvement to prepare and empower health professionals improve quality health care delivery. 


\section{Human, physical, material and financial resources to facilitate quality health care delivery}

In this section, participants were given six items that were related to human, material, and financial resources in order to determine how they were facilitating quality health care delivery. These items are illustrated in Table 8.

Table 8 Frequencies on patient safety $(n=2 I)$

\begin{tabular}{|c|c|c|c|}
\hline Statements & $\begin{array}{l}\text { Agree } \\
\text { f (\%) }\end{array}$ & $\begin{array}{l}\text { Neutral } \\
\text { f (\%) }\end{array}$ & $\begin{array}{l}\text { Disagree } \\
\text { f (\%) }\end{array}$ \\
\hline $\begin{array}{l}\text { Item I: Patients safety is well considered and assured by all } \\
\text { health professionals (care givers). }\end{array}$ & $15(7 \mid \%)$ & $3(14.2)$ & $3(14.2 \%)$ \\
\hline $\begin{array}{l}\text { Item 2: Patient is always involved to add value to quality care } \\
\text { delivery and challenges faced in quality health care planning. }\end{array}$ & $10(48 \%)$ & $7(33 \%)$ & $4(19 \%)$ \\
\hline $\begin{array}{l}\text { Item 3: Patients' needs are regularly assessed and integrated } \\
\text { into strategic planning to improve quality health care delivery } \\
\text { and to ensure that their expectations are included in quality } \\
\text { planning }\end{array}$ & $15(7 \mid \%)$ & $3(\mid 4.2 \%)$ & $3(14.2 \%)$ \\
\hline $\begin{array}{l}\text { Item 4: Patients' complaints are studied by the health } \\
\text { professionals to identify patterns and prevent problems } \\
\text { reoccurring. }\end{array}$ & $10(48 \%)$ & $7(33 \%)$ & $4(19 \%)$ \\
\hline
\end{tabular}

Item 1: Fourteen (67\%) of the participants agreed that health facilities had adequately trained health professionals to facilitate quality health care delivery at all health facility levels while four (19\%) opted for neutral and three (14\%) disagreed.

Item 2: Eight (38\%) of the participants agreed that the resources (human, material, infrastructure, finance) were equitably distributed and utilized to facilitate quality health care delivery; however, five $(24 \%)$ opted for neutral and eight (38\%) disagreed.

Item 3: With regard to availability of internal budget to ensure the successful implementation of a quality improvement programme; nine $(43 \%)$ agreed, eight (38\%) opted for neutral, and four $(19 \%)$ disagreed.

Item 4: The design and setting of health facility infrastructure do meet agreed quality improvement standards to address patients' health needs. On this continuum; 13(62\%) agreed, four (19\%) were neutral while four $(19 \%)$ disagreed.

Item 5: There are quality teams consisting of health professionals, management, patient, and stakeholders that analysis, evaluate, and compare quality health care results. In this area; seven $(33 \%)$ agreed, eight (38\%) were neutral while six (29\%) disagreed.

Table 9 Frequencies on information system $(n=2 I)$
Item 6: There was a continual professional development training programme to improve quality health care delivery. Ten (48\%) respondents agreed, four (19\%) were neutral while seven $(33 \%)$ disagreed.

On the constructs of human, physical, material, and financial resources; respondents had diverse views that centred on disagreements that resources were not equitable distributed, as shown by the highest $38 \%$. Nine (43\%-48\%) agreed that health facilities had neither internal budget nor good plans implemented for continual professional development to enhance quality improvement activities. That pointed at weakness and inadequate training on QI and QA. Health professionals alluded that they lacked knowledge and aptitudes to respond to the increasing demands of patients. The results indicated that health professionals were de motivated, which was a significant explanation for the weakness and errors in the health care system.

\section{Patient safety}

Patient safety is one of the most important components in quality health care delivery. In this study, participants were given four items that related to quality health care delivery Table 9 .

\begin{tabular}{|c|c|c|c|}
\hline Statements & $\begin{array}{l}\text { Agree } \\
\mathrm{f}(\%)\end{array}$ & $\begin{array}{l}\text { Neutral } \\
\text { f (\%) }\end{array}$ & $\begin{array}{l}\text { Disagree } \\
\mathrm{f}(\%)\end{array}$ \\
\hline $\begin{array}{l}\text { Item I: The hospitals collect a wide range of data and } \\
\text { information on quality of care and services. }\end{array}$ & $6(29 \%)$ & $7(33 \%)$ & $8(38 \%)$ \\
\hline $\begin{array}{l}\text { Item2: The hospital uses a wide range of data and } \\
\text { information on quality of care and services for reporting } \\
\text { incidences, feedback, and planning for improvement. }\end{array}$ & $10(48 \%)$ & $8(38 \%)$ & $3(14.2 \%)$ \\
\hline $\begin{array}{l}\text { Item 3: There is active involvement of health professionals in } \\
\text { determining what data and information are collected for the } \\
\text { purpose of improving quality health care and services delivery }\end{array}$ & $12(57 \%)$ & $5(24 \%)$ & $4(19 \%)$ \\
\hline $\begin{array}{l}\text { Item 4: The information on quality health care is regularly } \\
\text { shared with the clients / stakeholders to improve care and } \\
\text { service delivery }\end{array}$ & I5(7|\%) & $6(29 \%)$ & $0(0 \%)$ \\
\hline
\end{tabular}


Item 1: Fifteen (71.4\%) of the participants agreed that patients' safety was well considered and assured by all health professionals (care givers), three (14.3\%) remained neutral while four (14.3\%) disagreed.

Item 2: Ten (48\%) of the participants agreed that patients were always involved to add value to quality health care delivery and challenges faced in quality health care planning, seven (33\%) were neutral while four $(19 \%)$ disagreed.

Item 3: Fifteen (71.4\%) participants agreed that patient's needs were regularly assessed and integrated into strategic planning to improve quality health care delivery and to ensure that their expectations were included in quality planning, three (14.3\%) remained neutral while three $(14.3 \%)$ disagreed.

Item 4: In addition to patients' needs, 10(48\%) of the participants agreed that patients' complaints were studied by the health professionals to identify patterns and prevent problems from reoccurring, seven (33\%) opted for neutral while four (19\%) disagreed.
The majority (71\%) of the respondents agreed that patients' safety was well-considered by all health professionals and that patients' needs were regularly assessed and integrated into strategic planning to improve quality health care. However, $33 \%$ of the respondents decided to remain neutral while $19 \%$ disagreed on this continuum.

On the patient safety construct, respondents agreed that health facilities were patient focused, as shown in the high percentage that ranged between $48 \%-71 \%$. That indicated there was consideration of patient safety, as well as regular assessment and investigation of patients' health needs. On the contrary, 33\% disagreed with this statement, which indicated differences in quality health care delivery.

\section{Information to facilitate quality health care delivery}

Information and data on quality of care and services for reporting incidences, feedback, and planning for improvement were regarded as crucial aspects of quality health care delivery. In this section, respondents were given four items as illustrated in Table 10.

Table 10 Frequencies on monitoring and evaluation $(n=21)$

\begin{tabular}{|c|c|c|c|}
\hline Statements & $\begin{array}{l}\text { Agree } \\
f(\%)\end{array}$ & $\begin{array}{l}\text { Neutral } \\
\text { f (\%) }\end{array}$ & $\begin{array}{l}\text { Disagree } \\
\text { f(\%) }\end{array}$ \\
\hline $\begin{array}{l}\text { Item I: There is continual monitoring and evaluation to ensure that quality } \\
\text { improvement programmes are effectively and efficiently implemented in } \\
\text { agreement with the policy documents. }\end{array}$ & II (7|\%) & $0(0 \%)$ & $6(29 \%)$ \\
\hline $\begin{array}{l}\text { Item 2: There are quality indicators to measure processes, outputs, and } \\
\text { outcomes of hospital care services. }\end{array}$ & II (7|\%) & $0(0 \%)$ & $6(29 \%)$ \\
\hline $\begin{array}{l}\text { Item 3: The hospital services are regularly and systematically monitored to track } \\
\text { any deviations or changes, and to take corrective measures and prevention of } \\
\text { errors during treatment and care. }\end{array}$ & $14(67 \%)$ & $7(33 \%)$ & $0(0 \%)$ \\
\hline $\begin{array}{l}\text { Item 4: The outcomes of quality improvement at health facilities are reported } \\
\text { annually to facilitate quality planning. }\end{array}$ & $10(48 \%)$ & $6(29 \%)$ & $5(24 \%)$ \\
\hline $\begin{array}{l}\text { Item 5: The health facilities have tools for collecting data and measurements } \\
\text { strategies (surveys, self-assessment, audits, and supervisory visits). }\end{array}$ & II (52\%) & $6(29 \%)$ & $4(19 \%)$ \\
\hline $\begin{array}{l}\text { Item 7: The hospital services and programmes are audited and accredited by a } \\
\text { recognised professional body. }\end{array}$ & $16(76 \%)$ & $3(\mid 4.2 \%)$ & $2(10 \%)$ \\
\hline $\begin{array}{l}\text { Item 8: The equipment and supplies at health facilities are regularly checked to } \\
\text { make sure they comply with quality requirements. }\end{array}$ & II (52\%) & $8(38 \%)$ & $2(10 \%)$ \\
\hline
\end{tabular}

Item 1: Six $(29 \%)$ of the respondents agreed that the hospitals collected a wide range of data and information on quality of care and services delivery, seven (33\%) remained neutral while eight (38\%) disagreed.

Item 2: On the statement that the hospital uses a wide range of data and information on quality of care and services for reporting incidences, feedback, and planning for improvement; 10 (48\%) agreed, eight $(38 \%)$ opted for neutral while three $(14.2 \%)$ disagreed.

Item 3: Twelve (57\%) of the respondents agreed that health facilities provided active involvement of health professionals in determining what data and information were collected for the purpose of improving quality health care and services delivery, five $(24 \%)$ remained neutral while four (19\%) disagreed.

Item 4: Fifteen (71\%) of the respondents agreed, and six (29\%) disagreed that the information on quality health care was regularly shared with the client / stakeholders to improve care and service delivery.

On information to facilitate quality health delivery, only one construct was considered not to be significantly observed. Thirty-eight per cent of the respondents disagreed that the hospital did collect data on quality of care and services. The majority of respondents between $57 \%-71 \%$ agreed with the statement that health professionals are actively involved in the regular sharing of information with the clients to improve care and services.

\section{Monitoring and evaluation to facilitate quality health care delivery}

On monitoring and evaluation, respondents were given eight items to determine how quality health care delivery was monitored and evaluated at various health facilities.

Item 1: Eleven $(71 \%)$ of the respondents agreed that the quality improvement programme was effectively and efficiently implemented in agreement with the policy documents while six (29\%) disagreed with the statement.

Item 2: Eleven (71\%) of the respondents agreed that quality indicators to measure processes, outputs, and outcomes of hospital services did exist while six (29\%) disagreed with the statement. 
Item 3: Fourteen $(67 \%)$ of the participants agreed that the hospital services were regularly and systematically monitored to track any deviations or changes with the purposes of taking corrective measures and to prevent errors during care and treatment while seven (33\%) disagreed.

Item 4: Ten (48\%) of the participants agreed that the outcomes of quality improvement at health facilities was reported annually to facilitate quality planning, six $(29 \%)$ remained neutral while five $(24 \%)$ disagreed.

Item 5: Eleven (52\%) of the participants agreed that health facilities had tools for collecting data and measurements strategies (surveys, self-assessment, audits, supervisory visits), six (29\%) remained neutral while four (19\%) disagreed.

Item 6: Sixteen $(76 \%)$ of the participants agreed that the hospital services and programmes were audited and accredited by a recognized professional body while three $(14.2 \%)$ of the respondents were neutral and two $(10 \%)$ disagreed.

Item 7: Eleven (52\%) of the respondents agreed that the equipment and supplies at health facilities were regularly checked to make sure they comply with quality requirements and eight $(38 \%)$ of the respondents remained neutral while two $(10 \%)$ of the respondents disagreed.

There were high agreement and consistency on most of the statements of these items as indicated by high percentages in the range of $52 \%-76 \%$. Three-quarters $(76 \%)$ of the respondents agreed that hospital services and programmes were audited and accredited by a recognized professional body, there was continual monitoring and evaluation $(71 \%)$, existence of quality indicators to measure processes, outputs and outcomes $(71 \%)$, as well as tools for collecting data $(52 \%)$. The rest $14.2 \%-48 \%$ were either neutral or disagreed Table 11 .

The monitoring and evaluation just like research seemed to be the most contentious construct of all components. There were high percentages of agreement (48\%-71\%); however, an average of 33\%$38 \%$ remained neutral that most likely indicated that those components were not well-known or understood to help health professionals address the challenges faced in day-to-day health care and services delivery Table 12 .

Table II Frequencies on research ethics $(n=2$ I)

\begin{tabular}{|c|c|c|c|}
\hline Statements/items & $\begin{array}{l}\text { Yes } \\
\text { f (\%) }\end{array}$ & $\begin{array}{l}\text { Neutral } \\
f(\%)\end{array}$ & $\begin{array}{l}\text { No } \\
\text { f (\%) }\end{array}$ \\
\hline $\begin{array}{l}\text { Item I: Is the national research act regulating human participants in biomedical research to } \\
\text { ensure patient safety? }\end{array}$ & $5(23.85)$ & $3(\mid 4.3 \%)$ & $13(62 \%)$ \\
\hline $\begin{array}{l}\text { Item 2: Are there clear research guidelines on fundamental ethical principles and ethical issues } \\
\text { for health professionals and patients? }\end{array}$ & $9(43 \%)$ & $2(10 \%)$ & $10(48 \%)$ \\
\hline $\begin{array}{l}\text { Item 3: Does the hospital conduct patient safety research to detect and reduce harmful } \\
\text { medical practices? }\end{array}$ & $6(29 \%)$ & $5(24 \%)$ & $10(48 \%)$ \\
\hline $\begin{array}{l}\text { Item 4: Is patients' consent prioritised to safeguard privacy on medical records or specimens } \\
\text { used for research purposes? }\end{array}$ & $14(68 \%)$ & $3(14.3 \%)$ & $4(19 \%)$ \\
\hline $\begin{array}{l}\text { Item 5: Does the hospital use scientifically designed methods to review medical records, } \\
\text { observations, surveys, or interviews (data and statistics) to understand the magnitude and } \\
\text { causes of unsafe patient care and inferior service delivery? }\end{array}$ & $8(38 \%)$ & $6(29 \%)$ & $7(33.3 \%)$ \\
\hline $\begin{array}{l}\text { Item 5: Are potential risks involved in patient safety research submitted to research } \\
\text { committees for analysis and review before approval? }\end{array}$ & $9(43 \%)$ & $3(14 \%)$ & $9(43 \%)$ \\
\hline $\begin{array}{l}\text { Item 6: Do the hospitals conduct surveys to determine patients' satisfaction to improve care } \\
\text { and service delivery? }\end{array}$ & $9(41.2 \%)$ & $6(29 \%)$ & $4(19 \%)$ \\
\hline
\end{tabular}

Table 12 Frequencies on utilisation of data to evaluate and adjust quality improvement processes $(n=2$ I)

\begin{tabular}{llll}
\hline Statements/items & $\begin{array}{l}\text { Yes } \\
\mathbf{f ( \% )}\end{array}$ & $\begin{array}{l}\text { Neutral } \\
\mathbf{f ( \% )}\end{array}$ & $\begin{array}{l}\text { No } \\
\mathbf{f}(\%)\end{array}$ \\
\hline Item I: Clinical indicators to facilitate quality assessment. & $12(57 \%)$ & $5(24 \%)$ & $4(19 \%)$ \\
Item 2: Number of patients treated. & $17(81 \%)$ & $1(5 \%)$ & $3(14.3 \%)$ \\
Item 3: Complication registrations. & $11(52 \%)$ & $4(19 \%)$ & $6(29 \%)$ \\
Item 4: Incidence reporting system. & $17(81 \%)$ & $1(5 \%)$ & $3(14.3 \%)$ \\
Item 5: Interviews / surveys with / among patients. & $12(57 \%)$ & $5(24 \%)$ & $3(14.3 \%)$ \\
Item 6: Assessment of guidelines compliance. & $12(57 \%)$ & $4(19 \%)$ & $5(23.3 \%)$ \\
\hline
\end{tabular}

Research and indicators to facilitate quality health care and service delivery

Health professionals can no longer base their practice on rituals and unchallenged principles of tradition, especially on the issues related to quality health care delivery at the health facilities. Health professionals should be motivated to become intelligent users of research. Brink et al. ${ }^{14}$ suggest that for health professionals to be 
motivated, they need to consider the place of reach in professionals practice and to provide sound information on which they can base changes for improvement of quality services provided to clients. However, these services need to be guided by the ethical principles; such respect to persons, beneficence, and justice. In agreement with the above statement, respondents in this section were given six items to determine the application of research and indicators to facilitate quality health care delivery.

Item 1: The majority of the respondents $(13,62 \%)$ indicated there was no national research act regulating human participants in biomedical research to ensure patient safety, five (24\%) agreed while three (14\%) remained neutral.

Item 2: Nine (43\%) of the respondents indicated that health facilities had clear research guidelines on fundamental ethical principles and ethical issues for health professionals and patients, $2(9 \%)$ remained neutral while the majority $(10,48 \%)$ disagreed with the statement.

Item 3: The majority of the participants $(10,48 \%)$ indicated that the hospital did not conduct patient safety research to detect and reduce harmful medical practices, six (29\%) agreed while five (24\%) remained neutral.

Item 4: Fourteen $(67 \%)$ of the respondents agreed that patients' consent was prioritized to safeguard privacy on medical records or specimens used for research purposes, three (14.3\%) remained neutral while four (19\%) disagreed.

Item 5: Eight (38\%) of the respondents agreed that hospitals used scientifically designed methods to review medical records, observations, surveys, or interviews (data and statistics) to understand the magnitude and causes of unsafe patient care and lousy service delivery; six (29\%) remained neutral while seven (33.3\%) disagreed.

Item 6: Nine (43\%) of the respondents were agreed that potential risks were involved in patient safety research submitted to research committees for analysis and review before approval, three (14\%) were neutral while nine (43\%) did not support this statement.

Item 7: Nine $(43 \%)$ of the respondents agreed that hospitals did conduct surveys to determine patients' satisfaction to improve care and service delivery, six (29\%) were neutral while four (19\%) did not agree with the statement.

On research components, respondents had negative views with low scores on yes scale. Although respondents agreed that patient's consent was prioritized to safeguard privacy on medical records or specimens used for research purposes. Most had strong disagreement which indicated that research was not prioritized to facilitate quality health care delivery, as shared by high percentages between $48 \%$ and $62 \%$ respectively. On the research continuum, there was high level of disagreement in most of the items. Most respondents (68\%) stated that patients' consent was a priority while $43 \%$ stated that there were clear research guidelines. However, a good number of respondents between $48 \%-62 \%$ indicated that there were no adequate national regulations, no clear research guidelines on fundamental ethical principles and ethical issues for health professionals and patients of health research, and no vigorous research to determine the level of deviations on patient safety in attempt to detect and reduce harmful medical practices.

\section{Utilization (availability) of data to evaluate and adjust processes for quality health care delivery}

The knowledge gained through research allows health professionals to make better decisions and plan better strategies for the future. The data is only valuable when it is being utilized by those who need it. To support this statement, respondents were given six items to determine the availability of data to evaluate and adjust processes for quality health care delivery.

Item1: Twelve (57\%) of the respondents supported that clinical indicators did exist to facilitate quality assessment in health facilities, five $(24 \%)$ were neutral while four (19\%) did not support the statement.

Item 2: The majority of the respondents $(17,81 \%)$ supported that information about the number of patients treated was available, one $(5 \%)$ was neutral while three (14\%) disagreed.

Item 3: Complication on registration; eleven (52\%) said yes; four $(19 \%)$ were neutral while six (29\%) said no.

Item 4: Incidences reporting system; seventeen (81\%) said yes, one $(5 \%)$ neutral while three $(14.3 \%)$ said no to this component.

Item 5: Interviews/surveys with/among patients; twelve (57\%) said yes, five $(24 \%)$ were neutral while three $(14.3 \%)$ said no to this statement.

Item 6: Assessment of compliance with the guidelines; twelve (57\%) said yes, four $(19 \%)$ were neutral while five $(23.3 \%)$ said there was no compliance.

The results on utilization of data indicated that health facilities were very well on course in terms of generating, collecting, analyzing, and utilizing of data. That, however, contradicted the statements about research, which indicated that health facilities were either not involved or just consumers of data collected at a national level of other entities without a deeper understanding how the information was shared to assist with improving care and service delivery.

\section{Conclusion}

This paper described the experiences of managers in leadership positions to facilitate quality health care delivery in the health facilities in MoHSS. An overview of variables was outlined and presented in tabular form, which provided concrete results. The experiences of both managers in leadership positions indicated consistent agreement with regarding to availability of policies and guidelines, leadership, resources, patient safety, information, research monitoring and evaluation to facilitate quality health care delivery. The findings revealed that quality improvement policy and guidelines were aligned to the strategic objectives of the MoHSS to priorities, identify, and address gaps in quality health care delivery. There is visionary and strong leadership, which support health professionals to ensure active involvement in setting priorities for planning of quality health care improvement.

On the contrary, the findings also pointed out those monitoring tools were available to facilitate quality health care delivery in the health care facilities. Quality teams, indicators to measure processes, outputs, and outcomes of hospital care services were found to be adequate, regularly and systematically monitored to track any deviations or changes, and to take corrective measures and prevention of errors during treatment and care. However, health facilities were not collecting, nor analyzing data and information for reporting incidences, feedback, and planning to improve quality health care delivery. This was also hampered by inadequate physical facility, which denote detrimental work environment, against quality standards. No clear research guidelines, especially in regulating human participants in biomedical research to ensure patient safety. 
Furthermore, non-involvement of patients in health care planning and decisions contributed to poor quality services and difficulties to address health needs promptly.

\section{Recommendation}

i. Communicate the purpose of the institutional change strategy clearly and how it affects all departments, including health care facilities.

ii. Describe measurable objectives for implementing the change strategy and vision at the health care facilities.

iii. Establish systematic structures to strengthen supervision that facilitates the implementation of the quality improvement programme at the health care facilities.

iv. Provide support to health professionals to develop quality improvement measures and standardized instruments or tools with well-defined data elements, data collection, and data analyses methods to ensure that information is understood and applicable in the same way regardless of who refers or applies it.

v. Re-define and re-align job descriptions to match the roles and responsibilities of health professionals in order to enhance quality improvement and quality assurance at the health care facilities.

vi. Conduct surveys to distinguish between factors that motivate and the ones that dissatisfy the health professionals to bid the public health care facilities farewell

vii. Design practical motivational strategies according to specific categories that would ameliorate the situation.

viii. Identify the most affected health categories that are mostly leaving and try to investigate the most pertinent reasons for leaving.

ix. Recognize and reward progress in implementing change at health care facilities.

x. Provide proactive leadership to effectively guide and respond to resistance to change at the MoHSS health care facilities.

xi. Define the criteria for allocation and distribution of resources to ensure equity and accessibility of materials and equipment at the health care facilities.

xii. Determine the reporting format, frequency, and responsibilities of the respective officials to receive reports for immediate feedback and required action thereof.

xiii. Constitute an independent team for monitoring and evaluating QI/QA activities at the health care facilities.

xiv. Develop the terms of reference for the QI and QA Monitoring and Evaluation Committee.

\section{Acknowledgements}

None.

\section{Conflict of interest}

The authors declare no conflict of interest.

\section{References}

1. Ministry of Health and Social Services. Report of the Presidential Commission of Inquiry: Ministry of Health and Social Services. Namibia: Springer; 2013

2. Ministry of Health and Social Services, Final report. Assessment of the National Quality Management System Used to Monitor and Improve Quality Health Service Provision in Hospitals and Health Centers in Namibia. Windhoek, Namibia: Springer; 2014.

3. World Health Organization. The World Health Report 2000. Health Systems: Improving Performance. Geneva, Switzerland: World Health Organization; 2000.

4. Offei A, Sagoe K, OwusuAcheaw E, et al. Health care quality assurance manual for a regional-led, institutional -based quality assurance programme. Eastern Regional Health Administration \& Liverpool School of Tropical Medicine. 2004

5. Institute of Medicine. Crossing the quality chasm: A new health system for the $21^{\text {st }}$ century. Committee on quality of health care in america. institute of medicine (us) committee on quality of health care in America USA; 2001.

6. Whittaker S, Lynam FP, Burns $\mathrm{D}$, et al. Introducing quality assurance to health service delivery - some approaches from South Africa, Ghana and Kenya. Int J Qual Health Care. 1998;10(3):263-267.

7. McLaughlin CP, Kaluzny AD. Continuous quality improvement in health care. Theory, Implementations and Applications. 3rd ed. USA: Jones and Bartlett Publishers; 2006.

8. Meyer JA, Carroll SS, Kutyla T, et al. Hospital quality: ingredients for success-overview and lessons learned. 2004. p. 1-40.

9. Murray CJ, Frenk J. A Framework for assessing the performance of health systems. Bull World Health Organ. 2000;78(6):717-731.

10. Berwick D. Continuous improvement as an ideal in health care. $N$ Engl $J$ Med. 1989;320(1):53-56

11. Polit DF, Beck CT. Nursing Research. Generating and Assessing Evidence for Nursing Practice. 9th ed. USA: Wolters Kluwer/Lippincott Williams, Wilkins; 2012.

12. Andre L. Designing and doing survey research. UK: Sage Publications; 2012.

13. Babbie E. The Basic of Social Research. USA: Springer; 2008

14. Sekaran U. Research methods for business. 4th ed. USA: John Wiley, Sons; 2003.

15. Nunnally JC. Psychometric theory. USA: Springer; $1967.640 \mathrm{p}$

16. Churchill GA. A Paradigm for Developing Better Measures of Marketing Constructs. Journal of Marketing Research. 1979;64-73.

17. Brink H, Van Der Walt C, Van Rensburg G. Fundamentals of the research methodology for health care professionals. 6th ed. Cape Town, South Africa: Juta and Co; 2011.

18. Nieswiadomy RM. Foundations of Nursing Research. 6th ed. New Jersey, USA: Prentice Hall; 2011.

19. Tavakol M, Dennick R. Making sense of Cronbach's alpha. International Journal of Medical Education. 2011;2:53-55.

20. Andy F. Discovering statistics using SPSS. 3rd ed. USA: SAGE Publication; 2009.

21. Beyer H, Holtzblatt K. Contextual Design. In Context Enterprises, Harvard, USA: Springer; 1999 
22. Brynard P, Hanekom SX. Introduction to research in Public Administration and related academic disciplines. 1st ed. Hatfield, South Africa, Pretoria: JL van Schaik Academic; 2005.

23. Creswell JW. Research Design: Qualitative and Quantitative Approaches. UK: Sage Publications; 1994.

24. Creswell J, Clark PV. Designing and Conducting Mixed Methods Research. Thousand Oaks, USA: Springer; 2007.

25. Cronbach A. A useful coefficient for assessing consistency; 1951.

26. Davis HL, Douglas SP, Silk AJ. Measure unreliability: A Hidden Threat to Cross-National Marketing Research. Journal of Marketing. 1981;45:98-108.

27. Han J, Kamber M. Data Mining: Concepts and Techniques. Netherland Morgan Kaufmann Publishers; 2006.
28. Howitt D, Cramer D. First steps in research and statistics. A Practical workbook for Psychology Students. London, UK: Springer; 2000.

29. Lynn J, Baily MA, Bottrell M, et al. The ethics of using quality improvement methods in health care. Ann Intern Med. 2007;146(9):666673.

30. Pallant J. A step by step guide to data analysis using SPSS program survival manual. 4th ed. Australia: Allen, Unwin; 2011.

31. Singh SP. What are we managing. Knowledge or information. 2007;37(2).

32. Streiner D. Starting at the beginning: an introduction to coefficient alpha and internal consistency. Journal of personality assessment. 2003;80(1):99-103.

33. World Health Organization. Quality of care. A process for making Strategic Choices in Health Systems Geneva. Switzerland: Springer; 2006. 